\title{
Linguistic theory and the debate on the origin of language
}

\author{
Ermenegildo Bidese
}

University of Trento

Over the last three decades, the study of the origin and evolution of human language has attracted more and more scholars from different disciplines, and earned a place in several internationally renowned symposia, such as the 51st Annual Meeting of the Societas Linguistica Europea, held in 2018 in Tallinn, where a workshop with 13 contributions was dedicated to 'New Directions in Language Evolution Research'. Furthermore, the question of the origin and evolution of language is a topic that attracts not only the scientific community but also the lay public.

According to Aitchison (1998:17), the renewed interest in this topic was made possible, after the ban of Paris, by the famous article of Pinker and Bloom (1990), which attempted to reconcile 'natural language' and 'natural selection'. This article restored an orthodox (neo)-Darwinian account of the investigation of the origin of language, which in turn - in Aitchison's (1998) reconstruction - led to the development of a flourishing research field. However, Chomsky (2017:297) has recently contested such reconstruction, pointing out that both European and American structuralism assumed language to be a social entity. As a consequence, in structuralist approaches language was investigated mainly in its extensional aspects, and less so in its intensional nature. This means that, for example, given a category like plurality, it was more important in such traditions to classify the external forms (i.e. the different morphemes) that realize it than to model the internal rules - and, crucially, the abstract representations on which our language knowledge operates - that encode it linguistically.

It was only with UG - continues Chomsky (2017) - that the problem of the "Basic Property" was addressed. This made it possible to tackle the issue of the 'evolvability' of language in the correct way. But even in the long journey of the generative enterprise, the question of the origin of language gradually became more tractable, as the knowledge of UG progressed, particularly with respect to the pervasiveness and the simplicity of its core operation (see Chomsky 2007; Berwick 2011). In addition, a landmark in evolutionary biology was, in Chomsky's (2017) eyes, the appearance of Lewontin's (1998) contribution about the evolution 
of cognition and the limits of the knowledge about the origin of cognitive capabilities - an issue which until now has been largely ignored by most researchers working in the field of the origin of language.

In order to enhance our understanding of the origin and evolution of language it is crucial to focus not so much on what language enables us to do, but rather on what its core property is. An admittedly very simple - but in my eyes striking example of what language is can be illustrated by this sentence in German:

(1) Er brachte seine Mutter um den Verstand he drove his mother out of (her) mind

The expression um den Verstand bringen 'to drive somebody out of her/his mind' is idiomatic. The verb bringen and the prepositional phrase um den Verstand form a lexical unit. In virtue of the syntactic property of V2, which characterizes Germanic languages (with the well-known exception of Modern English), the finite verb is taken to move out of its basic position into the left periphery of the sentence. Looking at the order of the constituents seine Mutter 'his mother' and um den Verstand 'out of mind' it is interesting to note that the sequence of these phrasal elements cannot be inverted (cf. (2)):

(2) *Er brachte um den Verstand seine Mutter

There is no other explanation as to why (2) is wrong than to assume a 'trace' or 'copy' in the original position of the verb, which determines that the correct order is that in (1), although brachte and um den Verstand are in (2) linearly adjacent. As a kind of 'syntactic black hole' the trace of the verb attracts the lexicalized prepositional complement without the need for this original copy of the verb to be pronounced. Our mind sees the original copy at the end of the sentence, but our articulatory-auditory system pronounces only the first copy in the V2 position.

Why should a system that is optimized for communication allow (1) and not (2)? Evidently, there is a system-internal restriction that determines the insertion of the propositional object um den Verstand into the position in (1) which holds even when the verb is raised to another position. This structure seems to depend much more upon our thought and its operating properties than upon other reasons (see also Piattelli-Palmarini 2010).

Every discussion about the origin and evolution of language should take into account such basic linguistic facts. As Chomsky says in the cited contribution, "[i]nquiry into the evolution of some biological system evidently can proceed only as far as its nature is understood. Lacking such understanding, its manifestations are likely to appear to be chaotic, highly variable, and lacking significant general properties" (Chomsky 2017:295). 
This is the purpose of this new scientific journal, Evolutionary Linguistic Theory (ELT), namely to contribute to the ongoing debate on the origin of language from an explicitly linguistic viewpoint which examines the complexity of the topic from well-grounded knowledge in theoretical linguistics (with its subsystems, i.e. psycholinguistics, neurolinguistics, language acquisition and language change, historical linguistics and philosophy of language) and reaching out into the contiguous scientific disciplines, such as psychology, philosophy and cognitive neuroscience.

In the following we give a list of matters that ELT is concerned with:

- The design of the language faculty. If the operation 'merge' is taken to be essential in order to have language, how pervasive is it? Is it a core mechanism for syntax or can it be found at any level of the grammar?

- The place and the role of the lexicon. Where is the lexicon located in the architecture of the language faculty? Should we assume a primitive categorial divide between verb and substantive?

- The question of protolanguage. Is the assumption of an intermediate stage between non-language and a fully developed language faculty theoretically sustainable? Is there any piece of evidence?

- Language and Thought. How is the computational mechanism linked to the CI-system? Which role does the operation 'merge' play for brain, mind and thought? Which grammatical relations can be assumed to represent the link between language and thought? Concerning this, which role does the subjectpredicate relation play? Which role does subordination play?

- Language, music and action. Rule-based hierarchical and compositional ordering of discrete elements into sequences can be find not only in human language, but also in music, and perhaps in action. This raises the question of whether the cognitive operations necessary to isolate, process, and integrate syntactically organized elements are specific to language or may be shared between domains. Which consequences follow and which conclusions can be drawn for the question of the origin of language?

- The origin of language: from $\mathrm{L}^{-1}$ to $\mathrm{L}^{\circ}$. What is the necessary and sufficient condition for having language? Should categorization be assumed as a necessary condition and features (edge and categorial features) as a sufficient condition for language?

- Internal vs. external reality. If internal reality is fundamentally molded by the language, which kind of connection can be assumed with the external world?

- Language, consciousness and subjectness. Which role can language have played in the origin of the modern human cognition and consciousness? 
- Shared intentionality. Conceding that perceptual/parsing considerations do play a role in language design, and assuming that this is mapped onto the left periphery of the sentence, which role may the performance interface play in the context of sharing motive?

The present issue opens with Giorgio Graffi's overview of the debates on the origin of language(s). He reconstructs the question of monogenesis vs polygenesis of human languages and its possible linguistic implications. The second contribution, by Rita Manzini, concerns the design of the Faculty of Language. She analyses Northern Italian subject clitics, raising the question of how microvariation can be reconciled with the idea of a small number of macroparameters, and concluding that parameter hierarchies are emergent properties of the interaction between the computational core of the Language Faculty and externalization. In the third contribution, Denis Delfitto, Chiara Melloni and Maria Vender address the issue of expletive negation arguing for a dynamic interaction of negation with the contextual determinants of implicated meaning. This calls for a view in which syntax is not simply compositionally interpreted, but rather it applies to the representations produced in a much richer cognitive setting. Finally, the last contribution, by Andreas Trotzke, deals with paratactic emotive utterances, which are typically characterized by overt repetition, and considers them as possible elements of a pre-Merge era.

I wish you a pleasant reading of this issue, hoping that it will generate a fruitful discussion.

\section{References}

Aitchison, J. (1998). On discontinuing the continuity-discontinuity debate. In J. Hurford, M. Studdert-Kennedy, \& C. Knight (Eds.), Approaches to the Evolution of Language: Social and Cognitive Bases (pp. 17-27). Cambridge: Cambridge University Press.

Berwick, R.C. (2011). All you need is merge: biology, computation, and language from the bottom up. In A. M. Di Sciullo \& C. Boeckx (Eds.), The Biolinguistic Enterprise: New Perspectives on the Evolution and Nature of the Human Language Faculty (pp. 461-491).

Oxford: Oxford University Press.

Chomsky, N. (2007). Approaching UG from Below. In U. Sauerland \& H.-G. Gartner (Eds.), Interfaces + Recursion = Language?: Chomsky's Minimalism and the View from Syntax-Semantics (pp. 1-29). Berlin / New York, Mouton de Gruyter.

Chomsky, N. (2017). Language architecture and its import for evolution. Neuroscience and Biobehavioral Reviews, 81, 295-300. https://doi.org/10.1016/j.neubiorev.2017.01.053 Lewontin, R.C. (1998). The evolution of cognition: questions we will never answer. In D. N. Osherson, D. Scarborough, \& S. Sternberg (Eds.), Methods, Models and Conceptual Issues: An Invitation to Cognitive Science, vol. 4 (pp. 107-132). Cambridge, MA: Massachusetts Institute of Technology Press. 
Piattelli-Palmarini, M. (2010). What is language, that it may have evolved, and what is evolution, that it may apply to language. In R. K. Larson, V. Déprez, \& H. Yamakido (Eds.), The Evolution of Human Language: Biolinguistic Perspectives (pp. 148-162). Cambridge: Cambridge University Press. https://doi.org/10.1017/CBO9780511817755.011

Pinker, S. \& Bloom, P. (1990). Natural language and natural selection. Behavioral and Brain Sciences, 13, 707-784. https://doi.org/10.1017/S0140525X00081061

\title{
Address for correspondence
}

\author{
Ermenegildo Bidese \\ Department of Humanities \\ University of Trento \\ Via Tommaso Gar 41 \\ 38122 Trento \\ Italy \\ e.bidese@lett.unitn.it
}

